\title{
Local ecotypic and species range-related adaptation influence photosynthetic temperature optima in deciduous broadleaved trees
}

\author{
Piotr Robakowski • Yan Li • Peter B. Reich
}

Received: 23 March 2011 / Accepted: 24 November 2011/Published online: 7 December 2011

(C) The Author(s) 2011. This article is published with open access at Springerlink.com

\begin{abstract}
Given prior evidence for local ecotypic and species-specific adaptation in trees, we hypothesized that: (1) Acer rubrum and Quercus rubra provenances with different climate origins should differ in photosynthetic temperature optimum $\left(T_{\text {opt }}\right)$ even after long-term growth in a common environment; (2) congeneric species Populus tremuloides and Populus deltoides with differing but overlapping ranges should not differ in $T_{\text {opt }}$ when co-occurring, due to the likelihood of both ecotypic thermal adaptation and phenotypic thermal acclimation. To address these questions, we investigated the temperature
\end{abstract}

Electronic supplementary material The online version of this article (doi:10.1007/s11258-011-0011-3) contains supplementary material, which is available to authorized users.

P. Robakowski ( $\square)$

Department of Forestry, Poznan University of Life

Sciences, Wojska Polskiego 69 St., 60-625 Poznan, Poland

e-mail: pierrot@up.poznan.pl

Y. Li · P. B. Reich

Department of Forest Resources, University of Minnesota, 115 Green Hall, 1530 Cleveland Ave. N., St. Paul, MN 55108-6112, USA

P. B. Reich

Hawkesbury Institute for the Environment, University of Western Sydney, Locked Bag 1797, Penrith,

NSW 2751, Australia responses of pairs of $A$. rubrum and $Q$. rubra provenances planted in a common garden and the temperature responses of $P$. tremuloides and $P$. deltoides at four sites where the species ranges overlap in Minnesota, USA. Both studies showed significant signals of temperature adaptation. The provenances of both A. rubrum and $Q$. rubra that originated from northern sites with lower ambient temperature had lower $T_{\text {opt }}$. This supported the hypothesis about the dominance of local ecotypic adaptation of photosynthesis to temperature despite opportunity for both long-term (12-year) acclimation to the common-garden temperature regime and short-term temperature acclimation. However, acclimation capacity to the temperatures experienced in the days and weeks before the gas exchange measurements differed among the contrasting provenances suggesting that the observed differences in $T_{\mathrm{opt}}$ could be due to either fixed genotypic differences (e.g., adaptive $T_{\text {opt }}$ ), acclimation of $T_{\text {opt }}$, or both. In contrast, the Populus species with the colder home range, $P$. tremuloides, showed significantly $(P<0.05)$ lower $T_{\text {opt }}$ on average than co-occurring $P$. deltoides. Thus, despite the opportunity for both ecotypic adaptation and local acclimation, phylogenetic inertia still constrained the species with the colder overall range to a different temperature optimum than the one with a warmer overall range. Our results also imply that rapid but modest climate change may create mismatches between photosynthetic physiology and local climate because of lags in population or species-level adaptation. 
Keywords Adaptation to temperature $\cdot$ Broadleaved tree species $\cdot$ Photosynthesis $\cdot$ Photosynthetic temperature optimum $\cdot$ Provenance $\cdot$ Photosynthetic temperature response curve

\section{Introduction}

There is evidence that species or ecotypes growing in colder environment often but not always have lower photosynthetic temperature optima $\left(T_{\text {opt }}\right)$ than those growing at higher temperatures (Björkman et al. 1972; Fryer and Ledig 1972; Slatyer 1977; Berry and Björkman 1980; Cavieres et al. 2000; Cunningham and Read 2002; Gunderson et al. 2010). Taxa can be adapted to their different thermal origins and thus differ in $T_{\text {opt }}$ when they grow in a common environment (Berry and Björkman 1980; Cunningham and Read 2002; Gunderson et al. 2010). However, it is not clear whether they would still show differences in $T_{\mathrm{opt}}$ even when co-occurring, since strong ecotypic adaptation to the common environment might erase any species-scaled differences. Additionally, acclimatization to the field conditions may erase any adaptive differences. Such variation in $T_{\mathrm{opt}}$ can be due to genetic differences in temperature optima (that would arise from adaptation to local thermal environments), physiological acclimation (i.e., phenotypic) to growth temperature, or both. Intra-specific differences in $T_{\mathrm{opt}}$ of chamber-grown tree seedlings have been long noted among populations originating from different thermal environments (Björkman et al. 1972; Fryer and Ledig 1972; Slatyer 1977). In some forest tree species interand intraspecific variation in $T_{\text {opt }}$ have been studied, but mostly in controlled conditions. Only a few studies included temperate or boreal tree species (e.g., Fryer and Ledig 1972; Gunderson et al. 2000; Ledig and Korbobo 1983; Wieser et al. 2010).

For temperate deciduous tree species, differences in $T_{\text {opt }}$ of species adapted to contrasting temperature environments were significant but small due to acclimation-temperature-driven shifts of $T_{\mathrm{opt}}$ (Gunderson et al. 2010). However, another study (Dillaway and Kruger 2010) found no evidence of either thermal acclimation of $T_{\mathrm{opt}}$ or of adaptive differences among species. However, there is to our knowledge no evidence of whether field grown trees of closely related taxa differing in their range differ in their $T_{\text {opt }}$ after growing for many years in common conditions (which gives extended opportunity for convergent acclimation).

In the present study, the photosynthetic temperature responses of deciduous broadleaved trees: Acer rubrum, Quercus rubra, Populus deltoides, and Populus tremuloides were investigated. In a 10-year-old common garden, pairs of southern and northern provenances of A. rubrum and $Q$. rubra presumably adapted to different temperatures of their origins were compared for their $T_{\text {opt }}$ derived from temperature-photosynthesis response curves. The photosynthetic temperature responses of congeneric $P$. deltoides and $P$. tremuloides were determined in situ, along a latitudinal gradient within the region where the geographic ranges of both species overlap.

Based on evidence of strong ecotypic thermal adaptation of photosynthesis (Fryer and Ledig 1972; Slatyer 1977; Berry and Björkman 1980; Ishikawa et al. 2007), we hypothesized that the A. rubrum and $Q$. rubra southern ecotypes adapted to warmer climates would show higher photosynthetic temperature optima than northern, cold adapted provenances. This would indicate that adaptation to the thermal conditions of origin would dominate over 10-year acclimation to common temperature in a common environment. An alternate hypothesis was that strong acclimation to local conditions would erase genotypic tendencies after a decade of common conditions.

In the trial along a geographical gradient, we tested the hypothesis that if $P$. tremuloides and $P$. deltoides ecotypes are primarily adapted to their local environment, individuals from a species with a colder overall range ( $P$. tremuloides) should still have the same temperature optima for photosynthesis as co-occurring individuals from a species with a warmer overall range (P. deltoides). Alternatively, however, if genetic predisposition with respect to photosynthetic temperature optima is closely related to the overall range of a species, individuals of a species with a colder overall range might have lower temperature optima than nearby individuals of a species with a warmer overall range even when growing in comparable thermal conditions.

\section{Materials and methods}

Study species

The general description of A. rubrum, Q. rubra, $P$. deltoides, and P. tremuloides was based on Forestry 
Compendium (2005) and Silvics (2004). The investigated species are native to North America and their geographical ranges overlap considerably, but they differ in the ecological requirements and areas of occurrence. Their climatic amplitudes within the natural distribution are given in Table 1.

Acer rubrum (L.) is one of the most abundant and widespread trees in eastern North America. Its range extends between the latitudes $50^{\circ} \mathrm{N}$ and $26^{\circ} \mathrm{N}$, and between the altitudes 0 and $1,800 \mathrm{~m}$ a.s.l. A. rubrum is classified as a sub-climax or mid-seral species, generally tolerant of shade in young age.

Quercus rubra (L.) is one of the most important trees in eastern North America. Its range extends between the latitudes $48^{\circ} \mathrm{N}$ and $31^{\circ} \mathrm{N}$ and between the altitudes 0 and $1,800 \mathrm{~m}$ a.s.l. Red oak can be considered a fire sub-climax species, mid-tolerant of shade that is eventually replaced by more shade-tolerant species in the absence of periodic fires.

Populus deltoides (Bartr. ex Marsh.) has a very wide natural distribution range in eastern, central, and southern North America (between the latitudes $50^{\circ} \mathrm{N}$ and $28^{\circ} \mathrm{N}$ ). It mostly grows along streams and on bottom lands. Cottonwood is very intolerant of shade showing the traits of a pioneer species.

Populus tremuloides (Michx.) is the most widely distributed tree in North America. It is quick to pioneer many different sites between the latitudes $69^{\circ} \mathrm{N}$ and $24^{\circ} \mathrm{N}$. Trembling aspen is a shadeintolerant, short-lived, wind-firm tree with a rapid initial growth rate.
Study sites Common-garden experiment with A. rubrum
and $Q$. rubra

From 12-year-old trees growing in provenance trials in the St. Paul campus of the University of Minnesota $\left(44^{\circ} 59^{\prime} \mathrm{N}, 93^{\circ} 11^{\prime} \mathrm{W}, \mathrm{MAT}=7^{\circ} \mathrm{C}, \mathrm{MAP}=703 \mathrm{~mm}\right)$, two contrasting provenances were chosen for both A. rubrum: southern "CWH" (Coweeta, North Carolina) and northern "Wisconsin", and Q. rubra: southern "Indiana" and northern "New York". Provenances were chosen due to differences in MAT, mean temperatures of growth season and annual sum of precipitation of their geographical origin (Table 2). In the provenance experiment, the A. rubrum and Q. rubra were grown in eight blocks. Six of the blocks were chosen at random for the measures of gas exchange. Both provenances within the species were alternately measured to obtain a similar distribution of $T_{\text {opt }}$ in July, August and September for each provenance. Mean, mean minimal, and mean maximal temperatures 3 and 10 days before the gas exchange measurements for the provenances and the number of curves in the periods between 23 July and 31 August (hot period), and between 1 and 29 September (cool period) are given in online resource Table 1. Two to four trees per species, provenance and block were measured to determine in situ their short-term photosynthetic temperature responses, but not all response curves were completed successfully (e.g., weather changes, equipment malfunction, etc.) and met statistical requirements (see below). In total, the curves obtained for 15 maples ( 7 'Wisconsin' and 8 'CWH') and 23 oaks (12 'Indiana', 11 'New York') were

Table 1 The estimates of the climatic amplitudes of the study species (Forestry Compendium 2005; Silvics 2004)

\begin{tabular}{|c|c|c|c|c|}
\hline Climatic characteristics & $\begin{array}{l}\text { Acer } \\
\text { rubrum }\end{array}$ & Quercus rubra & Populus deltoides & $\begin{array}{l}\text { Populus } \\
\text { tremuloides }\end{array}$ \\
\hline Mean annual temperature $\left({ }^{\circ} \mathrm{C}\right)$ & 1 to 24 & 3 to $18(4-16)$ & 12 to 16 & -3 to 11 \\
\hline $\begin{array}{l}\text { Mean maximum temperature } \\
\text { of warmest month }\left({ }^{\circ} \mathrm{C}\right)\end{array}$ & 20 to 34 & 23 to 33 & 22 to 30 & 16 to 23 \\
\hline $\begin{array}{l}\text { Mean minimum temperature } \\
\text { of coldest month }\left({ }^{\circ} \mathrm{C}\right)\end{array}$ & -24 to 13 & -18 to 5 & -10 to $12(8)$ & -30 to -3 \\
\hline Absolute minimum temperature $\left({ }^{\circ} \mathrm{C}\right)$ & -47 & -60 & -45 & -61 \\
\hline Mean annual rainfall (mm) & 620 to 1,670 & 600 to 1,300 (760 to 2,030$)$ & 380 to $3,000(380$ to 1,400$)$ & 180 to 1,300 \\
\hline Dry season duration (month) & 0 to 6 & 0 to 3 & 0 to 1 & 0 to 3 \\
\hline
\end{tabular}

The estimates from Silvics are given in parentheses if they differ from those from Forestry Compendium 
Table 2 The description of geographical origin and climate characteristics of Acer rubrum and Quercus rubra used in the provenance experiment

\begin{tabular}{|c|c|c|c|c|c|}
\hline Species & $\begin{array}{l}\text { Name of } \\
\text { Provenance }\end{array}$ & Nursery location & $\begin{array}{l}\text { Lat/long } \\
\text { altitude } \\
\text { a.s.l. (m) }\end{array}$ & $\operatorname{MAT}\left({ }^{\circ} \mathrm{C}\right)$ & $\begin{array}{l}\text { Average annual } \\
\text { precipitation } \\
(\mathrm{mm})\end{array}$ \\
\hline \multirow[t]{2}{*}{ Acer rubrum } & Wisconsin & $\begin{array}{l}\text { Greatlakes Nursery Co., } \\
\text { Wausau }\end{array}$ & $\begin{array}{l}45^{\circ} 37^{\prime} \mathrm{N} 89^{\circ} 25^{\prime} \mathrm{W} \\
481.5\end{array}$ & 4.8 & 917 \\
\hline & CWH & $\begin{array}{l}\text { Coweeta High \& Med. Seed } \\
\text { Source (North Carolina) }\end{array}$ & 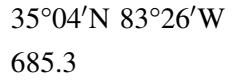 & 12.2 & 891 \\
\hline \multirow[t]{2}{*}{ Quercus rubra } & New York & $\begin{array}{l}\text { Saratoga Tree Nursery, } \\
\text { Saratoga Springs }\end{array}$ & $\begin{array}{l}43^{\circ} 19^{\prime} \mathrm{N} 73^{\circ} 56^{\prime} \mathrm{W} \\
246.3\end{array}$ & 7.0 & 1,299 \\
\hline & Indiana & Vallonia State Nursery & $\begin{array}{l}39^{\circ} 39^{\prime} \mathrm{N} 85^{\circ} 57^{\prime} \mathrm{W} \\
243.8\end{array}$ & 10.9 & 1,932 \\
\hline
\end{tabular}

The meteorological data were gathered from the meteorological stations situated closest to the sites of seeds origin (data source: NOAA-NCDC http://www4.ncdc.noaa.gov/cgi-win/wwcgi.dll?wwDI StnSrch StnID 20010921)

$M A T$ mean annual temperature

analyzed. An individual tree was treated as a true replication.

\section{Latitudinal transect of P. deltoides and P. tremuloides}

Photosynthetic temperature responses of $P$. deltoides and $P$. tremuloides were determined along the latitudinal gradient in the region of Minnesota where their geographic ranges overlap. Four locations with individuals of both species were chosen: Hubachek Wilderness Research Center near Ely ("Ely"), Cloquet Forestry Center in Cloquet ("Cloquet"), University of Minnesota St. Paul campus ("St. Paul"), Weaver Dunes Scientific and Natural Area situated near Kellogg (further called "Kellogg") (Table 3). At Kellogg and St. Paul the individuals of both species grew close to each other in similar microclimate and soil conditions, but at Cloquet and Ely, $P$. deltoides was found around $4-5 \mathrm{~km}$ from the site with $P$. tremuloides. In each location (other than noted below) young trees of both species (around 10 years old) originated from natural regeneration were found and used for the gas exchange measurements. To minimize potential differences in leaf phenology, the gas exchange measurements were begun at the northern sites near Cloquet (from 30 August to 1 September) and Ely (from 1 to 3 September) and were continued near Kellogg (9 to 11 September) and at the University campus (from 16 to 19 September). Mean, mean minimal, and mean maximal temperature ranges in four locations 3 and 10 days before the measurements of gas exchange are presented in online resource Table 2. The chosen locations differ in microclimate, e.g., the MAT in Ely is 2.8 and near Kellogg is $7.5^{\circ} \mathrm{C}$

Table 3 The geographical coordinates of the locations where the photosynthetic temperature optima of Populus deltoides and Populus tremuloides were determined, their climate characteristics, and the coordinates of the nearest meteorological stations

\begin{tabular}{|c|c|c|c|c|c|}
\hline Location & $\begin{array}{l}\text { Lat/long of } \\
\text { the locations }\end{array}$ & $\begin{array}{l}\text { Meteorological } \\
\text { station }\end{array}$ & $\begin{array}{l}\text { Lat/long of } \\
\text { the station }\end{array}$ & $\begin{array}{l}\text { MAT } \\
\left({ }^{\circ} \mathrm{C}\right)\end{array}$ & $\begin{array}{l}\text { Average annual } \\
\text { precipitation } \\
(\mathrm{mm})\end{array}$ \\
\hline $\begin{array}{l}\text { Ely (Hubachek Wilderness } \\
\text { Research Center) }\end{array}$ & $47^{\circ} 54^{\prime} \mathrm{N} 91^{\circ} 51^{\prime} \mathrm{W}$ & Ely Forestry Center & $47^{\circ} 54^{\prime} \mathrm{N} 91^{\circ} 51^{\prime} \mathrm{W}$ & 2.8 & 760 \\
\hline Cloquet (Clquet Forestry Center) & $46^{\circ} 42^{\prime} \mathrm{N} 92^{\circ} 31^{\prime} \mathrm{W}$ & Cloquet Forestry Center & $46^{\circ} 42^{\prime} \mathrm{N} 92^{\circ} 31^{\prime} \mathrm{W}$ & 4.5 & 770 \\
\hline Saint Paul (U of Minnesota campus) & $44^{\circ} 59^{\prime} \mathrm{N} 93^{\circ} 11^{\prime} \mathrm{W}$ & University of Minnesota & $44^{\circ} 58^{\prime} \mathrm{N} 93^{\circ} 16^{\prime} \mathrm{W}$ & 7.0 & 703 \\
\hline $\begin{array}{l}\text { Kellogg (Weaver Dunes Scientific } \\
\text { and Natural Area) }\end{array}$ & $44^{\circ} 15^{\prime} \mathrm{N} 91^{\circ} 56^{\prime} \mathrm{W}$ & Alma DAM 4, Wisconsin & $44^{\circ} 20^{\prime} \mathrm{N} 91^{\circ} 56^{\prime} \mathrm{W}$ & 7.5 & 834 \\
\hline
\end{tabular}

MAT mean annual temperature 
(Table 2). In each site five or six $P$. deltoides and $P$. tremuloides individuals were used for the gas exchange measurements.

\section{Measurements of gas exchange}

Thermal responses of photosynthesis were measured with a Li-Cor 6400 portable photosynthesis system (Li-Cor, Lincoln, NE, USA). In the common garden, gas exchange was measured in A. rubrum and Q. rubra between 23 July and 29 September 2008. Both provenances of Acer and both provenances of Quercus were alternately measured within similar temperature conditions over a short period. The gas exchange of $P$. deltoides and $P$. tremuloides was measured along a geographical gradient from 30 August to 19 September. Prior to each measurement, a healthy leaf from the southern lower crown part situated $\approx 1.8-2.2 \mathrm{~m}$ above ground was chosen and entered into the infra-red gas analyser leaf chamber at the ambient temperature for $20 \mathrm{~min}$. There was one temperature response curve per tree. In the leaf chamber PPF was maintained at the saturating level of $1,200 \mu \mathrm{mol} \mathrm{m} \mathrm{m}^{-2} \mathrm{~s}^{-1}$. Air flow was set at $400 \mu \mathrm{mol} \mathrm{s}^{-1}$, and $\mathrm{CO}_{2}$ concentration at $360 \mu \mathrm{mol} \mathrm{mol}^{-1}$. The leaf temperature was decreased to $\approx 3-7^{\circ} \mathrm{C}$ below the ambient temperature using the thermoelectric bloc and Li-Cor 6400-88 Expanded Temperature Control Kit within the cuvette, and then progressively increased at intervals until a distinct maximum and lowering of net $\mathrm{CO}_{2}$ assimilation rates were shown. The photosynthetic temperature response curves started from the mean initial leaf temperature between 14.7-20.8 (September- "cool period") and 17.3-23.9 ${ }^{\circ} \mathrm{C}$ (July-August— "hot period”). The lowest initial leaf temperature reached by the system was $13.1^{\circ} \mathrm{C}$ at the end of September (online resource 2). At each target temperature value the data were logged after around 6-8 min needed for equilibration of gas exchange, and three readings, 1 min apart, were taken at each set temperature. Cuvette humidity was not controlled, except for avoiding condensation at low temperatures. The amount of incoming air was routed through desiccant allowing incoming relative humidity (RH) not to exceed 65\%. In the experiment with Q. rubra and A. rubrum the increase in temperature in leaf chamber was accompanied by a decrease in $\mathrm{RH}$ and greater values of leaf-to-air vapor pressure deficit (VPD) ranging from 0.9 to $3.6 \mathrm{kPa}$. When the gas exchange was measured in $P$. deltoides and
P. tremuloides VPD in leaf chamber was more stable and ranged from 0.9 to $2.5 \mathrm{kPa}$.

Fitting of short-term temperature response curves of photosynthesis

To estimate $T_{\mathrm{opt}}$ and $A_{\mathrm{opt}}$ short-term photosynthetic temperature response curves were fitted using the following equation:

$A_{(\mathrm{T})}=A_{\mathrm{opt}}-b\left(T-T_{\mathrm{opt}}\right)^{2}$,

where $A_{(\mathrm{T})}$ is the measured net $\mathrm{CO}_{2}$ assimilation rate

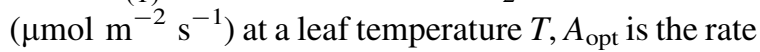
at $T_{\mathrm{opt}}$, and $b$ is a parameter describing the spread of the parabola. For the further analyses only these curves were used for which the coefficient of determination $\left(R^{2}\right)$ exceeded 0.70 and was statistically significant $(P<0.05)$. The vertex of each parabola was considered as the temperature optimum of photosynthesis. $T_{\text {opt }}, A_{\text {opt }}$, and $b$ were used as the parameters describing the photosynthetic temperature response for comparisons between the investigated provenances. Examples of the photosynthetic response curves fitting for an individual leaf are shown in supplementary material (online resource 2). To generate mean curves illustrated in Fig. 1, the Eq. 1 was used. For a given $A_{\text {opt }}$ and $T_{\text {opt }}$, a larger $b$ means a relatively more narrow temperature response parabola and a smaller $b$, a broader curve (Battaglia et al. 1996; Gunderson et al. 2010). The lowest and the highest leaf temperature values for each mean curve were calculated as the mean values from all replicate measurements. The mean $T_{\text {opt }}\left( \pm \mathrm{SE}\right.$, horizontal bars) and $A_{\text {opt }}( \pm \mathrm{SE}$, vertical bars) were shown as the vertex of each mean curve.

\section{Statistics}

The hierarchical analysis of variance in general linear model (GLM) with the independent variables: species and provenance nested in species, and the dependent variables: $A_{\text {opt }}, T_{\text {opt }}$ was applied to compare the photosynthetic temperature responses between $A$. rubrum and $Q$. rubra and between their provenances. The provenances of $A$. rubrum and $Q$. rubra within each species were compared a posteriori using the analysis of contrasts. All the statistical analyses were conducted at the significance level $\alpha=0.05$. 


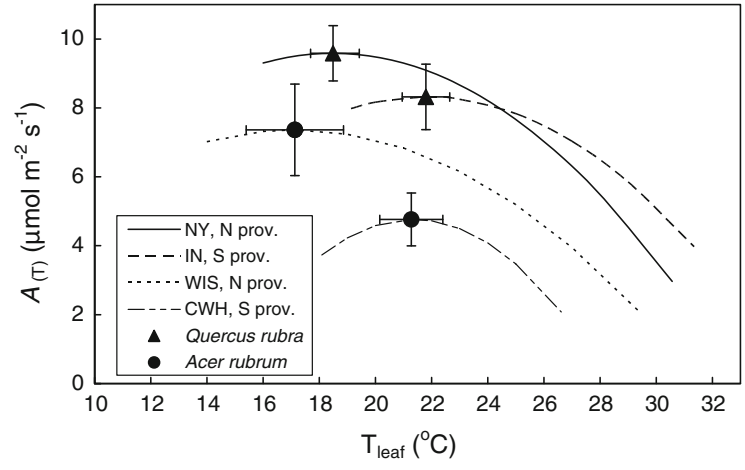

Fig. 1 Mean temperature response curves of net $\mathrm{CO}_{2}$ assimilation in Quercus rubra provenances "New York" (northern provenance, $n=11$ ) and "Indiana" (southern provenance, $n=12$ ), and in Acer rubrum provenances "Wisconsin" (northern provenance, $n=8$ ) and "CWH" (southern provenance, $n=7$ ) measured in common garden between 16 July and 29 September 2008. Mean curve for each provenance was obtained by fitting separate curves to each leaf and substituting the means of the parameters $T_{\text {opt }}, A_{\text {opt }}$, and $b$ into Eq. 1 . The mean $T_{\mathrm{opt}}\left( \pm \mathrm{SE}\right.$, horizontal bars) and $A_{\mathrm{opt}}( \pm \mathrm{SE}$, vertical bars) are given for each mean curve. Circles $A_{\mathrm{opt}}$ Vs. $T_{\mathrm{opt}}$ of $A$. rubrum; triangles $A_{\mathrm{opt}}$ vs. $T_{\mathrm{opt}}$ of $Q$. rubra. $N Y$ New York, $N$ northern Quercus rubra provenance, IN Indiana, $S$ southern Quercus rubra provenance, WI Wisconsin, $N$ northern Acer rubrum provenance, $C W H$ Coweeta High \& Med. Seed Source (North Carolina), $S$ southern Acer rubrum provenance. For ANOVA results, Table 4

Populus deltoides and P. tremuloides photosynthetic temperature responses were compared for the species and location effects using the two-way analysis of variance with interaction species $\times$ location. Both species of poplar in the different locations were compared a posteriori using the analysis of contrasts. The mean values of the parameter $b$ (Eq. 1) describing the spread of the parabola were compared between the populations within each species using a non-parametric Mann-Whitney $U$ test.

To determine potential short-term temperature acclimation of photosynthesis the relationships between $T_{\text {opt }}$ of the Acer and Quercus provenances, the Populus species and different temperatures (mean annual temperature, temperature of growth season, moving averages from $1,3,5,7$, or 10 days before the gas exchange measurements) were tested using the Pearson correlation coefficients and linear regression. The linear regression was also applied to analyze the relationships between the leaf temperature and ratio of internal $\mathrm{CO}_{2}$ partial pressure in leaf $\left(C_{i}\right)$, leaf-to-air VPD deficit, and between $C_{i}$ and net $\mathrm{CO}_{2}$ assimilation rate. The mean values of slope and constant were compared between the species and/or provenances with ANOVA or $t$ test at $P<0.05$. All the statistical analyses were conducted using Statistica 8.0 (Statsoft, Inc., Tulsa, OK, USA).

\section{Results}

Photosynthetic temperature responses of the common-garden-grown provenances

Photosynthetic temperature responses of A. rubrum and Q. rubra southern and northern provenances modeled using a quadratic equation (1) are presented in Fig. 1. The spread of the parabola described with the parameter $b$ did not significantly differ between the provenances within each species $(P>0.1$ in $U$ test). The left side of the curves was shorter than the right side because it was more difficult to decrease than to increase the leaf temperature below ambient (Fig. 1). Significant differences in $T_{\mathrm{opt}}$ within pairs of the A. rubrum provenances "Wisconsin" - "CWH" $(P=0.021, P$-probability obtained in the analysis of contrasts) and $Q$. rubra provenances "New York" - "Indiana" $(P=0.025)$ were noted. The provenance effect was highly significant for $T_{\mathrm{opt}}$ (Table 4). $T_{\text {opt }}$ of the more northern Acer provenance "Wisconsin" $\left(17.1 \pm 1.7^{\circ} \mathrm{C}\right)$ was lower than that of the southern provenance "CWH" $\left(21.4 \pm 1.1^{\circ} \mathrm{C}\right)$. For the more northern Quercus provenance "New York" $T_{\text {opt }}$ was $18.5 \pm 0.9^{\circ} \mathrm{C}$ and was significantly lower than those for the southern "Indiana" population $21.8 \pm 0.9^{\circ} \mathrm{C}$ (Fig. 1). All the values of $T_{\mathrm{opt}}$ are in the ranges of $T_{\text {mean(10) }}$ (the mean temperature 10 days before the gas exchange measurements) (CWH, New York) or $T_{\text {mean(3) }}$ (Indiana) except for $T_{\text {opt }}$ of Wisconsin which was lower by $1^{\circ} \mathrm{C}$ than $T_{\text {mean(3) }}$ (online resource Table 1). $T_{\text {opt }}$ of both northern provenances were in the low end of the range of $T_{\mathrm{opt}}$ compared with other studies (Gunderson et al. 2010; Silim et al. 2010). For both pairs of provenances $A_{\mathrm{opt}}$ was greater in the northern provenance than in the southern provenance, but these differences were not significant (Table 4; Fig. 1).

Effect of lack humidity control on photosynthetic temperature optimum

A rising temperature without full humidity control accompanied by an increase in VPD in the leaf 
Table 4 The results of the hierarchical ANOVA for Acer rubrum and Quercus rubra in which the species or provenance nested in species were the source of variance

\begin{tabular}{llrrrrr}
\hline Source of variance & Dependent variable & \multicolumn{1}{c}{ SS } & df & MS & \multicolumn{1}{c}{$F$} & $P$ \\
\hline Species & $A_{\text {opt }}$ & 75.45 & 1 & 75.45 & 8.61 & 0.006 \\
Prov(Species) & & 34.47 & 2 & 17.24 & 1.97 & 0.155 \\
Error & 297.85 & 34 & 8.76 & & \\
Species & $T_{\text {opt }}$ & 7.41 & 1 & 7.41 & 0.65 & 0.425 \\
Prov(Species) & & 129.21 & 2 & 64.61 & 5.68 & 0.007 \\
Error & & 386.60 & 34 & 11.37 & & \\
\hline
\end{tabular}

Dependent variables: $A_{\mathrm{opt}}$-maximum net $\mathrm{CO}_{2}$ assimilation rate measured at the optimum temperature of photosynthesis, $T_{\mathrm{opt}}-$ photosynthetic temperature optimum

Statistical terms: $S S$ sums of squares, $d f$ degrees of freedom, $F$ the value of Snedecor's function, $P$ probability

chamber may cause stomatal closure, thus a decrease in $C_{\mathrm{i}}$ and in $A$ at higher temperatures, and as a consequence a reduced $T_{\text {opt }}$. This could influence our observed $T_{\mathrm{opt}}$, and more important given the goals of this study, the differences among paired taxa. To test this hypothesis, internal $\mathrm{CO}_{2}$ partial pressure $\left(C_{\mathrm{i}}\right)$ and VPD as a function of leaf temperature were analyzed for each leaf. Then, the regressions between $C_{\mathrm{i}}$ and net $\mathrm{CO}_{2}$ assimilation rate were compared between the study provenances. There were not significant differences in slopes and in constants of linear regression $T_{\text {leaf }}$ vs. $C_{\mathrm{i}}$ between the provenances in $t$ test. Wisconsin and CWH - slope: $t=0.4, P=0.7$; constant: $t=-0.5, P=0.6$; df $=13$; New York and Indiana - slope: $t=-0.7, P=0.5$; constant: $t=-0.3$, $P=0.8 ; \mathrm{df}=21)$. The parameters of the regressions between $T_{\text {leaf }}$ and $C_{\mathrm{i}}$ are depicted in Table 5. The regression analysis between $T_{\text {leaf }}$ and VPD did not reveal significant differences between the provenances. It was thus corroborated that even if VPD increasing with $T_{\text {leaf }}$ could reduce $\mathrm{g}_{\mathrm{s}}, C_{\mathrm{i}}, A$, and $T_{\text {opt }}$, it did not significantly affect the differences in $T_{\text {opt }}$ between the provenances. The linear regression between $C_{\mathrm{i}}$ and $A$ was significant for all the study provenances except for the Acer CWH. For both Quercus provenances $A$ increased with $C_{\mathrm{i}}$ (New York $-y=0.07 x-1.16, \quad r^{2}=0.4, \quad P<0.001$; Indiana $\left.-y=0.03 x+2.81, r^{2}=0.1, P=0.001\right)$. For the Acer Wisconsin a decreasing trend $(y=$ $\left.-0.04 x+12.16, r^{2}=0.2, P=0.001\right)$ and for $\mathrm{CWH}$ a non-significant increase in $A$ with growing $C_{\mathrm{i}}$ $\left(y=0.01 x+2.09, \quad r^{2}=0.02, \quad P=0.2\right) \quad$ were observed. The Acer provenances did not differ in the mean slopes and intercepts. New York had the significantly higher slope than Indiana $(t=2.2$, $P=0.04 ; \mathrm{df}=21)$. At the same VPD and $C_{\mathrm{i}}$ net $\mathrm{CO}_{2}$ assimilation rate was higher in New York. $T_{\text {opt }}$ of New York was at higher $C_{\mathrm{i}}, A$, and lower VPD compared with $T_{\text {opt }}$ of Indiana. Thus, VPD increasing with leaf temperature might artificially decrease $T_{\mathrm{opt}}$ in
Table 5 Linear regression between the leaf temperature and internal $\mathrm{CO}_{2}$ partial pressure $\left(C_{\mathrm{i}}\right)$

The mean values of slope and constant, 95\% confidence interval for mean, minimum and maximum values (MinMax), and number of curves (n) are given

\begin{tabular}{lllllr}
\hline Species & Provenance & $\begin{array}{l}\text { Mean } \\
\text { slope }\end{array}$ & $\begin{array}{l}\text { Confidence interval } \\
-95 \% \text { to } 95 \%\end{array}$ & Min-Max & $n$ \\
\hline Acer rubrum & Wisconsin & 0.53 & -4.69 to 5.75 & -7.05 to 7.86 & 7 \\
& CWH & 1.78 & -3.96 to 7.51 & -7.24 to 15.13 & 8 \\
Quercus rubra & New York & -5.17 & -7.19 to -3.16 & -12.26 to -0.74 & 11 \\
& Indiana & -4.29 & -6.08 to -2.50 & -9.03 to 1.63 & 12 \\
\hline Species & Provenance & Mean & Confidence interval & Min-Max & $n$ \\
& & constant & $-95 \%$ to $95 \%$ & & $n$ \\
\hline \multirow{2}{*}{ Acer rubrum } & Wisconsin & 165.8 & 42.2 to 289.3 & -38.4 to 340.5 & 7 \\
& CWH & 126.4 & -15.1 to 267.9 & -177.3 to 351.2 & 8 \\
Quercus rubra & New York & 258.4 & 208.6 to 308.2 & 146.5 to 413.9 & 11 \\
& Indiana & 268.5 & 218.1 to 318.8 & 70.8 to 386.9 & 12 \\
\hline
\end{tabular}


the Quercus provenances. However, all the photosynthetic temperature response curves for the compared pairs of provenances were generated within the similar ranges of VPD, therefore it did not affect the differences in $T_{\mathrm{opt}}$ between the provenances. In comparison with Acer and Quercus both poplars maintained stable $C_{\mathrm{i}}$ with increasing leaf temperature and VPD was similarly correlated with leaf temperature in each species and location.

\section{Correlations between growth temperatures}

and optimum temperature for photosynthesis

$T_{\text {opt }}$ was positively related with the mean, maximum and minimum temperatures observed $1,5,7$, or 10 days before the gas exchange measurements in $\mathrm{CWH}$, but these correlations were not significant for Wisconsin (Table 6). For CWH the slopes of the regression between the different temperatures and $T_{\mathrm{opt}}$ ranged from 0.5 to 1.0 depending on the moving average. Wisconsin showed non-significant slopes between 0.4 and 1.5. The significant relationship was found between the $T_{\mathrm{opt}}$ and mean temperatures observed 1 and 5 days before the measurements. There were not significant correlations between growth temperatures and $T_{\mathrm{opt}}$ in the Quercus provenances except for Indiana and the relationship between $T_{\max (1)}$ and $T_{\mathrm{opt}}$ with a slope of 0.8 (Table 6). When both Acer provenances were pooled, $T_{\mathrm{opt}}$ was related with $T_{\max (3)}(r=0.7, P=0.005, n=38)$. $T_{\text {opt }}$ of the Quercus was not significantly related with growth temperatures when both provenances New York and Wisconsin were pooled.

Photosynthetic temperature responses of $P$. deltoides and $P$. tremuloides

The results of two-way ANOVA indicated that $P$. deltoides and $P$. tremuloides growing in the region where their geographical ranges overlap statistically differed with respect to $T_{\text {opt }}$, but not $A_{\text {opt }}$ (Table 7; Fig. 2). The species with the warmer overall range, $P$. deltoides, showed higher $T_{\mathrm{opt}}$ than $P$. tremuloides $\left(26.0 \pm 1.1\right.$ and $23.0 \pm 0.8^{\circ} \mathrm{C}$, respectively) when growing in similar thermal environments (Figs. 2, 3).

$T_{\text {opt }}$ did not depend on local location, however, indicating no evidence for long-term acclimation within the modest climate gradient among the four sites. For both species, $T_{\text {opt }}$ at the two sites cooler
Table 6 The relationship between the mean, mean minimum, and maximum temperatures observed $1,3,5,7$, or 10 days before the gas exchange measurements and photosynthetic temperature optima of the Acer rubrum and Quercus rubra provenances

\begin{tabular}{llllc}
\hline Temperature & Wisconsin & CWH & New York & Indiana \\
\hline$T_{\operatorname{mean}(1)}$ & 0.464 & $0.823^{*}$ & -0.537 & 0.475 \\
$T_{\min (1)}$ & 0.555 & $0.833^{*}$ & -0.415 & 0.103 \\
$T_{\max (1)}$ & 0.354 & $0.813^{*}$ & -0.558 & $0.668^{*}$ \\
$T_{\operatorname{mean}(3)}$ & 0.597 & $0.772^{*}$ & -0.427 & 0.063 \\
$T_{\min (3)}$ & 0.617 & $0.735^{*}$ & -0.412 & -0.201 \\
$T_{\max (3)}$ & 0.567 & $0.811^{*}$ & -0.402 & 0.440 \\
$T_{\operatorname{mean}(5)}$ & 0.559 & $0.804^{*}$ & -0.458 & 0.061 \\
$T_{\min (5)}$ & 0.543 & $0.789^{*}$ & -0.329 & -0.121 \\
$T_{\max (5)}$ & 0.564 & $0.819^{*}$ & -0.585 & 0.332 \\
$T_{\operatorname{mean}(7)}$ & 0.585 & $0.796^{*}$ & -0.287 & -0.129 \\
$T_{\min (7)}$ & 0.569 & $0.796^{*}$ & -0.203 & -0.198 \\
$T_{\max (7)}$ & 0.564 & $0.795^{*}$ & -0.383 & -0.019 \\
$T_{\operatorname{mean}(10)}$ & 0.546 & $0.751^{*}$ & -0.284 & 0.059 \\
$T_{\min (10)}$ & 0.553 & $0.747^{*}$ & -0.230 & 0.074 \\
$T_{\max (10)}$ & 0.537 & $0.754^{*}$ & -0.335 & 0.042 \\
\hline
\end{tabular}

The values of Pearson correlation coefficients $(r)$ with probability are given $(* 0.01 \leq P<0.05)$

Table 7 The results of the two-way ANOVA with interaction in which species (Populus deltoides and P. tremuloides), location, and interaction between the species and location $(\mathrm{S} \times \mathrm{L})$ were the sources of variance $(n=37)$

\begin{tabular}{llrrrrl}
\hline $\begin{array}{l}\text { Source of } \\
\text { variance }\end{array}$ & $\begin{array}{l}\text { Dependent } \\
\text { variable }\end{array}$ & SS & df & MS & $F$ & $P$ \\
\hline Species & $A_{\text {opt }}$ & 13.02 & 1 & 13.02 & 2.71 & 0.110 \\
Location & & 64.06 & 3 & 21.35 & 4.45 & 0.011 \\
$\mathrm{~S} \times \mathrm{L}$ & & 23.09 & 3 & 7.70 & 1.60 & 0.210 \\
Error & & 139.17 & 29 & 4.80 & & \\
Species & $T_{\text {opt }}$ & 79.00 & 1 & 79.00 & 4.63 & 0.040 \\
Location & & 5.15 & 3 & 1.72 & 0.10 & 0.959 \\
$\mathrm{~S} \times \mathrm{L}$ & & 35.20 & 3 & 11.73 & 0.69 & 0.567 \\
Error & & 495.16 & 29 & 17.07 & & \\
\hline
\end{tabular}

Dependent variables: $A_{\mathrm{opt}}$-maximum net $\mathrm{CO}_{2}$ assimilation rate measured at the optimum temperature of photosynthesis, $T_{\mathrm{opt}}$ - photosynthetic temperature optimum

Statistical terms: $S S$ sums of squares, $d f$ degrees of freedom, $F$ the value of Snedecor's function, $P$ probability

during the measurement period (mean daily maxima 21.8 and $24.8^{\circ} \mathrm{C}$, July-September 2008) did not differ from at the two warmer sites (mean daily maxima 26.9 


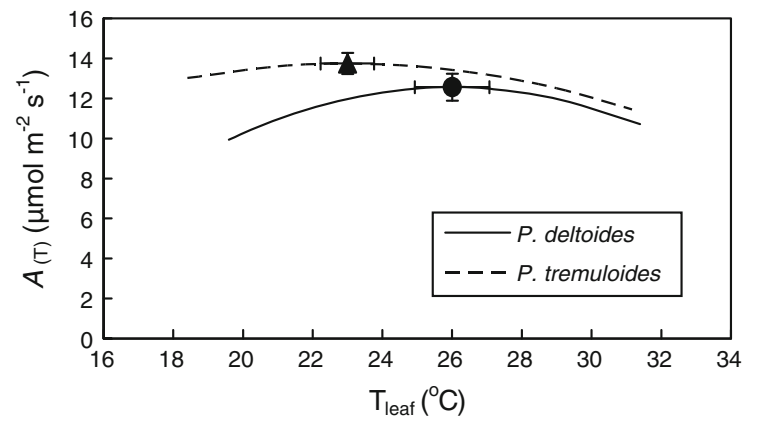

Fig. 2 Mean temperature response curves of net $\mathrm{CO}_{2}$ assimilation in Populus deltoides $(n=17)$ and Populus tremuloides $(n=20)$ measured along a geographical gradient in Minnesota. The gas exchange measurements were begun at the northern sites near Cloquet (from 30 August to 1 September) and Ely (from 1 to 3 September) and were continued near Kellogg (from 9 to 11 September) and at the University campus (from 16 to 19 September). Mean curve for each species was obtained by fitting separate curves to each leaf and substituting the means of the parameters $T_{\mathrm{opt}}, A_{\mathrm{opt}}$, and $b$ into Eq. 1 . The mean $T_{\mathrm{opt}}( \pm \mathrm{SE}$, horizontal bars) and $A_{\mathrm{opt}}$ ( $\pm \mathrm{SE}$, vertical bars) are given for each mean curve. $A_{(\mathrm{T})}$-net $\mathrm{CO}_{2}$ assimilation rate at a leaf temperature $T$; circle $A_{\mathrm{opt}}$ vs. $T_{\mathrm{opt}}$ of Populus deltoides, triangle $A_{\text {opt }}$ vs. $T_{\text {opt }}$ of Populus tremuloides. For ANOVA results, see Table 7

and $26.1^{\circ} \mathrm{C}$, July-September 2008). For P. deltoides, $T_{\text {opt }}$ was generally higher than mean daily maximum, but for $P$. tremuloides $T_{\mathrm{opt}}$ was generally lower than mean daily maximum except for Ely. $T_{\mathrm{opt}}$ of both poplars were higher than $T_{\text {mean(3) }}$ and $T_{\text {mean(10) }}$, but in the range or lower than $T_{\max (3)}$ and $T_{\max (10)}$ (online resource Table 2). Additionally, the more northern species had higher $A_{\text {opt }}$ than the southern species at the two northern sites (Cloquet and Ely), but not at the southern ones which was confirmed by the analysis of contrasts between-species within each location $(P<0.05)$ (Fig. 3).

$C_{\mathrm{i}}$ was $\approx 220 \mu \mathrm{mol} \mathrm{mol}{ }^{-1}$. The mean slopes and intercepts of the regression between $T_{\text {leaf }}$ and $C_{\mathrm{i}}$ did not significantly differ between the species and between the species within each location in ANOVA (slope: $F=1.3, \quad P=0.3 ; \quad F=0.3, \quad P=0.8 ; \quad$ intercept: $F=1.9, P=0.2, F=0.25, P=0.9)$. There were not significant differences between the species in the parameters of regression between $T_{\text {leaf }}$ and VPD. $T_{\text {opt }}$ of $P$. deltoids and $P$. tremuloides were not correlated with moving average temperatures $1,3,5,7$, and 10 days prior to the gas exchange measurements. In comparison with some Acer and Quercus photosynthetic response curves having a shorter left side at
$T_{\text {leaf }}<T_{\text {opt }}$, most of the photosynthetic response curves of the poplars had a regular parabolic shape.

The parabolic curves describing temperature responses of the poplars differed in spread determined by the parameter " $b$ " (Eq. 1). The mean value of " $b$ " was lower for $P$. tremuloides with flatter temperature response curves than $P$. deltoides; this difference was significant (Mann-Whitney $U$ test, Table 8; Fig. 2). The lower " $b$ " value means that $P$. tremuloides sustained net $\mathrm{CO}_{2}$ assimilation rates close to $A_{\text {opt }}$ at a greater interval of leaf temperatures compared with P. deltoides.

\section{Discussion}

The provenances of A. rubrum and $Q$. rubra originating from modestly colder growing season thermal conditions showed lower photosynthetic temperature optima $\left(T_{\text {opt }}\right)$ than those from warmer conditions, even after growing for many years together in a common garden (Fig. 1). These results confirmed the evidence of significant ecotypic thermal adaptation of photosynthesis in trees (shown previously for seedlings or saplings: Fryer and Ledig 1972; Berry and Björkman 1980; Cavieres et al. 2000; Cunningham and Read 2002), in this case being stronger than any tendency for long-term convergent acclimation. However, in natural conditions, it was impossible to separate genetic differences from differences in acclimation to prevailing temperatures in common garden. The differences observed among $T_{\text {opt }}$ of the contrasting taxa could be due to either fixed genotypic differences (e.g., adaptive $T_{\text {opt }}$ ), or genotypic differences in their decadal, seasonal and short-term acclimation of $T_{\text {opt }}$, or all of these (e.g., Battaglia et al. 1996; Gunderson et al. 2010).

Intraspecific variation of $T_{\mathrm{opt}}$ has rarely been investigated among deciduous broadleaved trees populations and those experiments were conducted in greenhouse, in open top chambers, or climate chambers after a short period of acclimation to growth temperature compared with our study (Ledig and Korbobo 1983; Gunderson et al. 2000; Weston and Bauerle 2007). It should be emphasized that in contrast to other studies where $T_{\text {opt }}$ for tree species and/or ecotypes was determined (Battaglia et al. 1996; Cavieres et al. 2000; Gunderson et al. 2000; Cunningham and Read 2002; Dillaway and Kruger 
Fig. 3 Mean temperature response curves of net $\mathrm{CO}_{2}$ assimilation in Populus deltoides and Populus tremuloides measured along a geographical gradient in Minnesota. Gas exchange was measured in four locations from north to south: Ely, Cloquet, University of Minnesota (St. Paul's campus), and Kellogg. Mean curve for each species and location was obtained as in Fig. 1. The mean $A_{\text {opt }}( \pm \mathrm{SE}$, vertical bars) and $T_{\mathrm{opt}}$ ( \pm SE, horizontal bars) are given for each mean curve. For ANOVA results, see Table 7

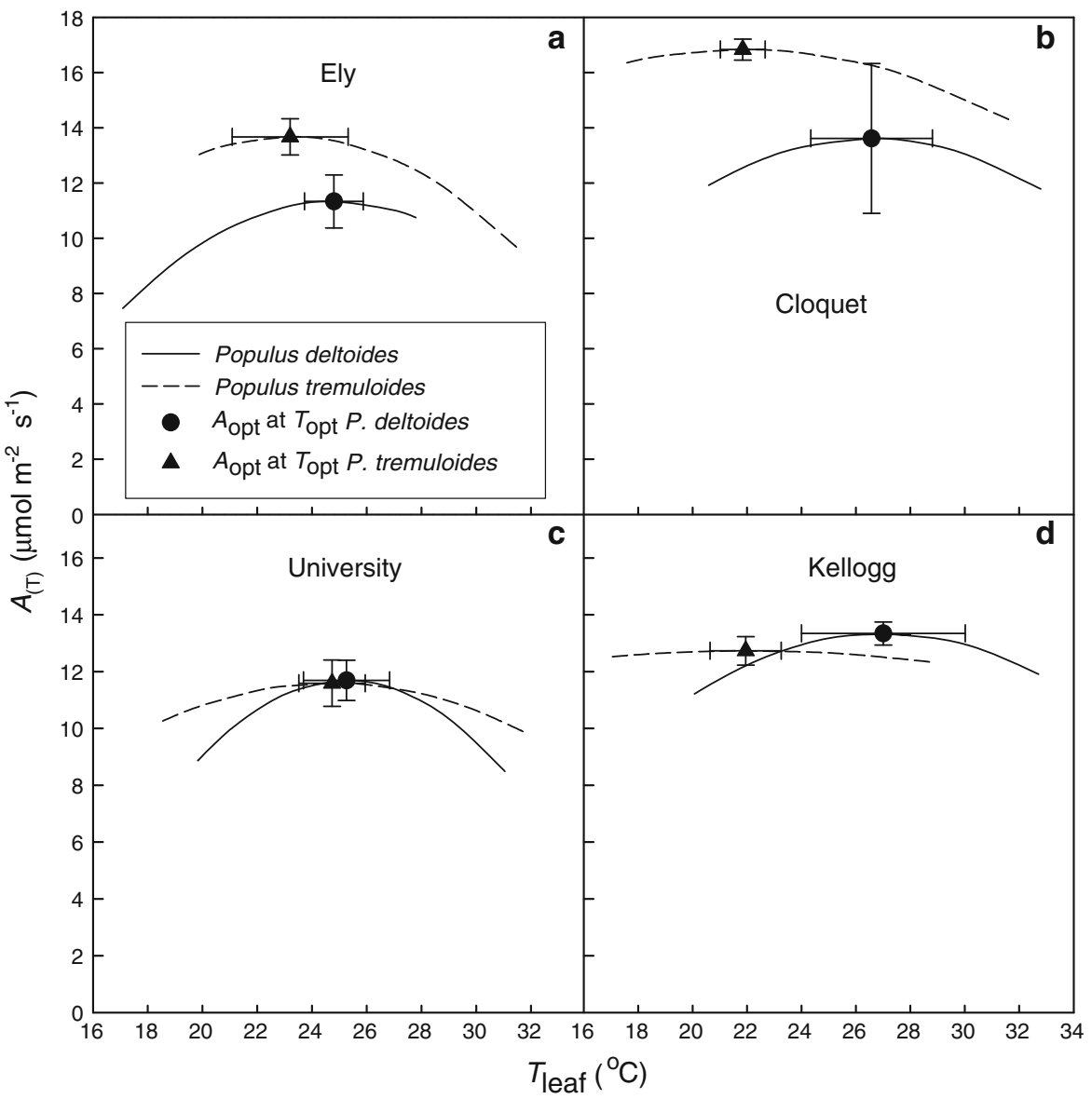

Table 8 Mean values $( \pm \mathrm{SE})$ of the parameter " $b$ " (Eq. 1) determining a spread of photosynthetic temperature response curves of Populus deltoides and Populus tremuloides in each locations separately and pooled

\begin{tabular}{llrlr}
\hline Location & P. deltoides & $n$ & $P$. tremuloides & $n$ \\
\hline Ely & $0.065 \pm 0.019$ & 3 & $0.058 \pm 0.015$ & 6 \\
Cloquet & $0.047 \pm 0.017$ & 4 & $0.026 \pm 0.005$ & 5 \\
University & $0.095 \pm 0.033$ & 5 & $0.035 \pm 0.014$ & 5 \\
Kellogg & $\mathbf{0 . 0 4 4} \pm \mathbf{0 . 0 1 1}$ & 5 & $\mathbf{0 . 0 0 9} \pm \mathbf{0 . 0 0 2}$ & 4 \\
Mean " $b$ " for the & $\mathbf{0 . 0 6 4} \pm \mathbf{0 . 0 1 2}$ & 17 & $\mathbf{0 . 0 3 4} \pm \mathbf{0 . 0 0 7}$ & 20 \\
$\quad$ & & & & \\
\hline
\end{tabular}

To compare the species, the Mann-Whitney $U$ test was applied. The mean " $b$ " values significantly different between the species at $P<0.05$ were marked with a bold font. $n$ number of curves used for the analysis

2010; Gunderson et al. 2010; Wieser et al. 2010), our results are the first providing evidence of intraspecific differences in $T_{\text {opt }}$ for field grown deciduous broadleaved trees growing over the long-term in a common environment. In contrast to our findings, though, Gunderson et al. (2000) did not find significant ecotypic differences in temperature optima between the seedlings populations of Acer saccharum acclimated for 3 years to growth temperature in open top chambers. However, our results are in agreement with those of Ferrar et al. (1989) who found differences in $T_{\text {opt }}$ between populations from contrasting thermal environments in Eucalyptus pauciflora Sieber ex A. Spreng. In earlier studies, ecotypic variation in $T_{\text {opt }}$ was found in evergreen trees originated from different altitudes (Fryer and Ledig 1972; Ferrar et al. 1989; Cavieres et al. 2000; Wieser et al. 2010), but not in deciduous trees from different altitudes or latitudes (Ledig and Korbobo 1983; Gunderson et al. 2000). However, Weston and Bauerle (2007) showed differences in photosynthesis between the thermally contrasting genotypes of A. rubrum. The Florida A. rubrum genotype had the higher $T_{\mathrm{opt}}$ than the Minnesota genotype. 
$T_{\text {opt }}$ for the study provenances ranged between 17.1 and $21.8^{\circ} \mathrm{C}$ and only the lowest value obtained for the northern A. rubrum provenance diverged from the range $20-25^{\circ} \mathrm{C}$ compiled for temperate deciduous tree species in Larcher (2003). Gunderson et al (2010) observed $T_{\text {opt }}$ ranging from 23 to $30^{\circ} \mathrm{C}$ for a $Q$. rubra provenance with a warmer thermal origin and environment than our provenances. Moreover, Gunderson et al. (2010) found in Liquidamber styraciflua that in autumn $T_{\text {opt }}$ averaged $17.3^{\circ} \mathrm{C}$, and in the warmest period (June) $T_{\text {opt }}$ was $30.9^{\circ} \mathrm{C}$ indicating strong plasticity in the optimum temperature. Hence it is not surprising to see differences in $T_{\text {opt }}$ values for a single species across sites and seasons.

$T_{\text {opt }}$ of all four taxa were low in comparison with mean daily maximal temperatures July-September at the study site in the year of measurements or at their sites of origin. However, $T_{\mathrm{opt}}$ was higher than the average growth temperature (May-Sept) at the sites of origin. In our study, generally, $T_{\text {opt }}$ was lower than maximal daytime summer temperatures. This is not necessarily sub-optimal because if $T_{\text {opt }}$ were scaled to the daily temperature maximum or higher, trees might photosynthesize at the highest level only for a very short period within a day when temperature was close to a daily maximum. Nonetheless, we cannot exclude that the low $T_{\text {opt }}$ of the provenances growing in common garden might be due to a lack of humidity control in the leaf chamber. A rising leaf temperature accompanied by an increase in VPD, stomatal closure, thus a decrease in $C_{\mathrm{i}}$ and net $\mathrm{CO}_{2}$ assimilation rate at higher temperatures might lead to a lower $T_{\text {opt }}$. Even though rising VPD might be a contributing reason for the low $T_{\mathrm{opt}}$ of oaks and maples, it did not influence significantly the differences in $T_{\text {opt }}$ between the study provenances because they did not differ in the mean slopes and constants of linear regression between the $T_{\text {leaf }}$ and $C_{\mathrm{i}}$ (Table 5), and VPD. All the temperature response curves of the compared provenances were generated at the similar VPD range. Gunderson et al. (2010) observed on few occasions, $C_{\mathrm{i}}$ decreased at the highest cuvette temperatures. Even then, dividing $A$ by $C_{\mathrm{i}}$ revealed nonstomatal decreases in $A$, i.e., the rate of $A$ per unit $\mathrm{CO}_{2}$ decreased at high temperatures, and the decline was far steeper than that produced from an $A / C_{\mathrm{i}}$ relationship. Decreasing $C_{\mathrm{i}}$ was thus not the cause of the decline in $A$ above $T_{\text {opt }}$, nor did it account for treatment differences, as VPD correlated with cuvette temperature, without regard to treatment. This is in agreement with our observations.

When $P$. deltoides and $P$. tremuloides sympatric populations were compared along a geographical gradient within the region of their overlapping ranges, genetic differences between the species with respect to their photosynthetic temperature responses outweighed any possible effects of adaptation and acclimation to local thermal environments. The lower $T_{\text {opt }}$ was shown by $P$. tremuloides - which has a large natural range area extended to northern Canadacompared with the more southern ranging temperate $P$. deltoides (Table 1).

Gunderson et al. (2010) also found significant differences in $T_{\text {opt }}$ among deciduous tree species differing in ranges. The differences in $T_{\text {opt }}$ to some extent corresponded to their thermal origins: two species from cooler, more northerly habitats had slightly lower $T_{\text {opt }}$ values than the others. It is noteworthy that in our study the difference in $T_{\text {opt }}$ of around $3^{\circ} \mathrm{C}$ was found in the area where the ranges of $P$. tremuloides and $P$. deltoides overlapped. However, in common gardens established along a $900 \mathrm{~km}$ latitudinal transect from northern Wisconsin to southern Illinois, these poplars did not differ in $T_{\text {opt }}$ (Dillaway and Kruger 2010). Although it is impossible to completely reconcile these differences, the inconsistency with our results could be caused by differences in "Materials and methods" section. We used individuals growing in natural conditions and measured gas exchange in situ in four different locations, whereas poplars used by Dillaway and Kruger (2010) originated from one seed source, they had initially been grown in a greenhouse, and then they were planted in watered and fertilized common gardens.

Our results are one of the first providing evidence of interspecific differences in $T_{\text {opt }}$ for field grown deciduous broadleaved trees within the region of the study species overlapping ranges. Both $P$. tremuloides and $P$. deltoides have large geographic ranges, therefore we hypothesized that their ecotypes at the study sites would be both adapted to and acclimated to the local thermal niches. However, we did not find differences in $T_{\text {opt }}$ between trees from the different localities. This may have been because the study sites were not far apart. A lack of ecotypic acclimation to local growth temperature with respect to $T_{\text {opt }}$ might also be caused by a high variation of uncontrolled factors which 
influenced photosynthetic temperature responses, such as thermal history, radiant energy received by the plant before gas exchange measurements, and other interacting factors, such as drought, water vapor deficit, nutrient availability, and leaf age (Fryer and Ledig 1972; Reich et al. 1998; Zhou et al. 2007). Additionally, the more northern species had higher $A_{\text {opt }}$ than the southern species at the northern but not at the southern sites which might suggest better adaptation of $P$. tremuloides to colder climate when compared with the co-occurring species.

In our study, significant correlations were found between mean, mean maximal, and mean minimal temperatures observed for the $1,3,5,7$, and 10 days before the gas exchange measurements and $T_{\mathrm{opt}}$ of the Acer CWH provenance and between $T_{\max (1)}$ and $T_{\mathrm{opt}}$ of the Quercus Indiana provenance. These relationships found between the moving average temperatures and $T_{\mathrm{opt}}$ suggest that short-term thermal acclimation influenced $T_{\mathrm{opt}}$ of the study provenances. Similarly, Gunderson et al. (2010) found an even stronger relationship of $T_{\mathrm{opt}}$ to temperature history for four deciduous tree species including Q. rubra. Compared with our experiment, these authors gathered $T_{\mathrm{opt}}$ from May to November encompassing a longer period with higher temperature differences. In contrast, there was no correlation between the moving average temperatures and $T_{\text {opt }}$ of both Populus. The gas exchange measurements in poplars were accomplished within a short period in September which did not encompass seasonal temperature changes. Thus, all the curves of photosynthetic temperature responses for $P$. deltoids and tremuloides were generated in "cold" period. Shortterm or seasonal temperature acclimation was also not found in Eucryphia lucida (Cunningham and Read 2002) and in P. tremuloides, Betula papyrifera, and P. deltoides (Dillaway and Kruger 2010).

The results of our study confirmed that the differences between two closely related species and pairs of provenances with differing climate origins could all arise from genotypic differences, and/or genotypic differences in acclimation of $T_{\text {opt }}$ to prevailing temperatures. Both adaptation and acclimation (e.g., Battaglia et al. 1996; Gunderson et al. 2010) of $T_{\mathrm{opt}}$ of tree species and ecotypes to thermal growth conditions could have important consequences for their potential responses to global warming. Temperate tree species with high intrinsic $T_{\text {opt }}$ and/or acclimation potential may respond positively to increased temperatures. The ability to sustain net $\mathrm{CO}_{2}$ assimilation rates close to maximum across a wider interval of leaf temperature was greater in $P$. tremuloides than $P$. deltoides. Hence it is possible that our study species had different plasticity in instantaneous response to temperature. If generalizable, the between-species differences in $T_{\mathrm{opt}}$ and in ability to sustain $A$ close to a maximum at a great interval of leaf temperature might influence the responses of $P$. tremuloides and $P$. deltoides to global warming at sites where they co-occur. The lower $T_{\text {opt }}$ of $A$ could in theory help to constrain the southern limits of its range if no acclimation occurred as temperatures grow warmer. In contrast, temperate $P$. deltoides with high $T_{\mathrm{opt}}$ may positively respond to increased temperatures. However, differences in physiological mechanisms of adaptation and acclimation plasticity of photosynthetic parameters, and enormous uncertainty about these, make it difficult to model plant responses to increased temperatures. Better understanding of patterns of $T_{\mathrm{opt}}$-which would reflect photosynthetic adaptation and ability to adapt to the changing thermal environment — could be used to improve bioclimatic models.

In conclusion, our results provided evidence that provenances of $A$. rubrum and $Q$. rubra originated from different thermal environment exhibited persistent differences in photosynthetic temperature responses likely due to their ecotypic adaptation to the thermal conditions of their origin, and that such differences persisted despite years of potential acclimation to a common growth condition and short-term temperature acclimation. A genetic predisposition, also was shown by differences in $T_{\mathrm{opt}}$ between sympatric populations of $P$. deltoides and $P$. tremuloides, consistent with the generally warmer-ranging species being better matched to warmer temperatures than the northerly distributed one. All three pairs of comparable taxa suggest that climate origins matter to temperature-based photosynthesis, even for plants long acclimated to local sites.

Acknowledgments We thank Prof. Jacek Oleksyn for thoughtful comments on the manuscript, Ms Cindy Buschena for excellent technical assistance, and the Wilderness Research Foundation for funding support. Piotr Robakowski was supported by the research scholarship from the Kosciuszko Foundation and Yan $\mathrm{Li}$ by the Chinese Government $\mathrm{PhD}$ Scholarship. 
Open Access This article is distributed under the terms of the Creative Commons Attribution Noncommercial License which permits any noncommercial use, distribution, and reproduction in any medium, provided the original author(s) and source are credited.

\section{References}

Battaglia M, Beadle C, Loughhead S (1996) Photosynthetic temperature responses of Eucalyptus globulus and Eucalyptus nitens. Tree Physiol 16:81-89

Berry J, Björkman O (1980) Photosynthetic response and adaptation to temperature in high plants. Annu Rev Plant Physiol 31:491-543

Björkman O, Pearcy RW, Harrison AT, Mooney H (1972) Photosynthetic adaptation to high temperatures: a field study in Death Valley, California. Science 175(4023): 786-789

Cavieres LA, Rada F, Azócar A, García-Núñez C, Cabrera HM (2000) Gas exchange and low temperature resistance in two tropical high mountain tree species from Venezuelan Andes. Acta Oecol 21(3):203-211

Cunningham SC, Read J (2002) Comparison of temperate and tropical rainforest tree species: photosynthetic responses to growth temperature. Oecologia 133:112-119

Dillaway ND, Kruger EL (2010) Thermal acclimation of photosynthesis: a comparison of boreal and temperate tree species along a latitudinal transect. Plant Cell Environ 33(6):888-899

Ferrar PJ, Slayter RO, Vranjic JA (1989) Photosynthetic temperature acclimation in Eucalyptus species from diverse habitat, and a comparison with Narium oleander. Aust J Plant Physiol 16:199-217

Forestry Compendium (2005) Acer rubrum, Quercus rubra In: Forestry Compendium, Global Edition. Centre for Agriculture and Bioscience International (CAB International), Wallingford, UK

Fryer HJ, Ledig FT (1972) Microevolution of the photosynthetic temperature optimum in relation to the elevational complex gradient. Can J Bot 50:1231-1235

Gunderson CA, Norby JR, Wullschleger DS (2000) Acclimation of photosynthesis and respiration to simulated climatic warming in northern and southern populations of Acer saccharum: laboratory and field evidence. Tree Physiol 20:87-96

Gunderson CA, O'Hara KH, ChM Campion, Walker AV, Edwards NT (2010) Thermal plasticity of photosynthesis: the role of acclimation in forest responses to a warming climate. Glob Change Biol 16:2272-2286

Ishikawa K, Onoda Y, Hikosaka K (2007) Intraspecific variation in temperature dependence of gas exchange characteristics among Plantago asiatica ecotypes from different temperature regimes. New Phytol 176:356-364

Larcher W (2003) Physiological plant ecology. Berlin Heidelberg New York, Springer

Ledig FT, Korbobo DR (1983) Adaptation of sugar maple populations along an altitudinal gradients: photosynthesis, respiration, and specific leaf weight. Am J Bot 70(2):256265

Reich BP, Walters BM, Tjoelker MG, Vanderklein D, Buschena C (1998) Photosynthesis and respiration rates depend on leaf and root morphology and nitrogen concentration in nine boreal tree species differing in relative growth rate. Funct Ecol 12:395-405

Sage RF, Kubien DS (2007) The temperature response of $\mathrm{C}_{3}$ and $\mathrm{C}_{4}$ photosynthesis. Plant Cell Environ 30:1086-1106

Silim SN, Ryan N, Kubien DS (2010) Temperature responses of photosynthesis and respiration in Populus balsamifera L.: acclimation versus adaptation. Photosynth Res. doi: 10.1007/s11120-010-9527-y

Silvics of North America (2004) Hardwoods, vol 2. http://www. na.fs.fed.us/spfo/pubs/silvics_manual/volume_2/silvics_ v2.pdf

Slatyer RO (1977) Altitudinal variation in the photosynthetic characteristics of snow gum, Eucalyptus pauciflora Sieb. ex Spreng. IV. Temperature response of four populations grown at different temperatures. Aust J Plant Physiol 4:583-594

Weston DJ, Bauerle LW (2007) Inhibition and acclimation of $\mathrm{C}_{3}$ photosynthesis to moderate heat: a perspective from thermally contrasting genotypes of Acer rubrum (red maple). Tree Physiol 27:1083-1092

Wieser G, Oberhuber W, Walder L, Spieler D, Gruber A (2010) Photosynthetic temperature adaptation of Pinus cembra within the timberline ecotone of the Central Austrian Alps. Ann For Sci 67. doi:10.1051/forest/2009094

Zhou X, Liu X, Wallace LL, Luo Y (2007) Photosynthetic and respiratory acclimation to experimental warming for four species in a tallgrass prairie ecosystem. J Integr Plant Biol 49:270-281 